This is a repository copy of "Thermal balance of large scale parabolic trough plants: A case study" in the Depósito de Investigación de la Universidad de Sevilla

Version: Author Accepted Version

Citation: A.J. Sánchez, A.J. Gallego, J.M. Escaño \& E.F. Camacho. "Thermal balance of large scale parabolic trough plants: A case study". Solar Energy - ISSN 0038-092X. Vol. 190, pp. 69-81. Septiembre 2019.10.1016/j.solener.2019.08.001

To cite this publication, please use the final published version (if applicable). Please check the document version above.

Copyright: Other than for strictly personal use, it is not permitted to download, forward or distribute the text or part of it, without the consent of the author(s) and/or copyright holder(s), unless the work is under an open content license such as Creative Commons.

Takedown policy: Please contact us (idus@us.es) and provide details if you believe this document breaches copyrights. We will remove access to the work immediately and investigate your claim 


\title{
Thermal balance of large scale parabolic trough plants: A case study
}

\author{
A.J. Sánchez*, A.J. Gallego, J.M. Escaño, E.F. Camacho \\ Departamento de Ingeniería de Sistemas y Automática, Universidad de Sevilla, Camino de los Descubrimientos s/n, 41092 Sevilla, Spain
}

\begin{abstract}
The main control objective in commercial solar parabolic plants is to track the average temperature of all the loops around a reference set by the operator, by manipulating the flow of a synthetic oil. Due to the large number of loops existing in current solar plants and the vast extension that they cover, obtaining a precise knowledge of every loops efficiency becomes a very challenging task. Parameters such as loops reflectivity, tube absorptance, optical efficiency may exhibit a great disparity due to dirt accumulated and atmospheric conditions. Because of this, the most efficient loops achieve higher temperatures and the collectors may have to be set out of focus in many cases.

This paper presents a case study on a simulation model of a large scale parabolic plant, $50 \mathrm{MW}$, in which a control of the aperture of the solar field loops inlet valves is applied through a nonlinear optimization problem. The goal is to reduce the imbalance of loops temperature caused by the difference in efficiencies. The idea is opening the input valves of the most efficient loops to increase the incoming flow-rate and reducing the flow in the less efficient loops. This will prevent, in many cases, the activation of the defocus control avoiding energy losses and minimizing the deterioration of actuators.

The optimization problem will need estimations of the loops states and parameters. An Unscented Kalman Filter is used to estimate the loops temperatures states and a concentrated parameter model is used to estimate the loops efficiencies. A loop clustering is implemented to avoid high computation times. Simulation results showing thermal balance of the field minimizing the defocusing actions are presented.
\end{abstract}

Keywords: Solar Energy, Thermal balance, Optimization, Clustering, Defocus control

\section{Introduction}

Development and research in renewable sources of energy are being encouraged by the need to reduce the amount of $\mathrm{CO}_{2}$ emissions provoked by conventional electricity generation (fossil fuels) (Romero and González-Aguilar, 2014; Blanco and Santigosa, 2017). At present, among the renewable energies that are being more exploited we can highlight solar, wind and hydraulic.

This paper focuses in Concentrating Solar Power (CSP) plants with Parabolic Trough Collectors (PTC). Solar thermal technology has now passed its development phase and is now in operation (almost 100 commercial plants in 2017 (Pitz-Paal, R., 2018)). As a proof of this, we can mention the following solar power plants that have been operating in the recent years: Helios I (50 MW) (Helios I, 2019), Majadas I (50 MW) (Majadas I, 2019) and Mojave I/II (140 MW each) (Mojave Solar Project, 2019).

It is important to emphasize that one of the most relevant characteristics of this type of solar plants is the capacity to store energy (Liu et al., 2016; Alva et al., 2017;

\footnotetext{
*Corresponding author Tel.: +34 954487347

Email addresses: asanchezdelpozo@us.es (A.J. Sánchez), gallegolen@hotmail.com (A.J. Gallego), jescano@us.es (J.M. Escaño), ef camacho@us.es (E.F. Camacho)
}

Pelay et al., 2017; Sarbu and Sebarchievici, 2018), to be used later, e.g., when the sun has set. The storage of thermal energy can be done, generally, using steam (Prieto et al., 2018) or molten salt tanks (Roca et al., 2016; Peiró et al., 2018), being molten salts the best option when storage capacity is increased (González-Roubaud et al., 2017).

Generally, the objective to pursue in PTC CSPs is to keep temperature at the outlet of the solar field around a reference value or set-point by using the flow-rate of the fluid as a control signal. Part of the research related to this field has been carried out in the ACUREX solar field sited in Almería (Spain), both in simulation models and in real tests in the ACUREX facilities. The objectives that have been pursued in research related to the control of solar plants focus on temperature tracking, robustness and plant optimization, to name just a few. In Andrade et al. (2013), a practical Nonlinear Model Predictive Control is developed for outlet temperature reference tracking. Robustness and stability are included by adding, to the cost function and in the controller constraints, a Lyapunov function. An optimal operation in solar plants study is presented in Camacho and Gallego (2013). Authors proposed a three layer algorithm to increase the performance by calculating the optimal solar field outlet temperature. Lima et al. (2016) proposed a temperature control of a 
solar field by using a Filtered Dynamic Matrix Control in which the filter is used in the prediction error allowing the modification of the robustness and disturbance rejection properties of the original Dynamic Matrix Control algorithm. He et al. (2016) presented a model to determine the optimal day ahead offering strategy for CSP plants with TES, by solving an optimization problem which maximizes the expected total profit, in power markets. A Gain Scheduling Model Predictive Control (GS-GPC) is presented in Gallego et al. (2018) for field outlet temperature tracking of the new infrastructures for solar research (TCP-100) sited at Plataforma Solar de Almería (PSACIEMAT). In Sánchez et al. (2018b) preliminary results of a model based optimization for performance improvement of a solar trough plant, by means of field temperature homogenization, are presented. The strategy was applied to the ACUREX solar field showing power benefits when high outlet field temperatures are required. A new term penalizing the generation variation (cycling) is presented in Cojocaru et al. (2019), which is used for a scheduling strategy for CSPs. Authors showed that a a reduction in the generation cycling can extend the lifetime of the power block without reducing profits.

The ACUREX solar field consisted of 10 loops of 172 meters of length. Small solar fields such us the ACUREX field can be simplified to one equivalent collector loop. Considering that all the solar field is affected by similar levels of solar radiation and with loops having similar parameters is reasonable in small plants but not in large solar fields (Gallego and Camacho, 2012).

In large scale solar plants such as Helios I (90 loops, 110 hectares) or Solana (808 loops, 800 hectares), this type of global controllers may cause energy losses or unnecessary overreaction due to the temperature discrepancy between the different loops. This effect occurs not only due to the difference between the loops but also due to clouds. Controlling the average temperature of all loops presents a drawback: if the solar field has not a good thermal balance, namely, all the loops have similar optical efficiencies and flow-rate levels, some loops may reach much higher temperatures than the others. Furthermore, the optical efficiency of the loops can become very different due to reflectivity, collector shape, receiver tube efficiency, structural state of the collectors/loops and environmental factors. These imbalances in the optical efficiency may lead to the most efficiency loops to be defocused to avoid overheating problems (Sánchez et al., 2018b).

When a solar plant reaches a saturation point (maximum flow-rate and electric power production), it is easy to find situations in which part of the field is much warmer than others due to what has been previously mentioned. Some parts of the field will have to be defocused since the received solar radiation may be too high and the field temperature cannot be reduced by increasing the flow. Due to the aforementioned, the controller regulating the average solar field temperature by manipulating the main pumps flow, cannot cope with all the problems described above and new control strategies have to be developed.

In commercial solar trough plants, the inlet valves are usually used to achieve a hydraulic or static thermal balance. This is normally done on rare occasions. This can be done by increasing the aperture of the hottest loops input valves (increasing the flow levels) and reducing the aperture of the coldest loops input valves (decreasing the flow levels). In this paper a nonlinear optimization problem throughout the plant daily operation is presented to control the apertures of the valves, which dictates the flow to each loop, to obtain a thermal balance of the solar field. The goal is to reduce the discrepancy in the loops outlet temperature. A thermal balance of the field will avoid unnecessary defocusing actions. The optimization problem is based on a distributed parameters model (DPM) and therefore an estimation of the loops internal temperatures is needed. This is done using an Unscented Kalman Filter (UKF). The optical efficiencies are estimated using a concentrated parameter model. An analysis of the computation times depending of the number of the loops is shown. A clustering algorithm is applied in order to group loops with similar parameters to reduce the number of decision variables in the optimization problem. To simulate and validate the proposed strategy a $50 \mathrm{MW}$ nonlinear plant model is used.

The main advantages of the proposed optimization problem to control the inlet valves are:

1. Achieving a thermal balance of the field.

2. Reducing energy losses. Due to thermal balance defocusing actions will be reduced in many cases avoiding possible energy losses.

3. Reducing the deterioration of the actuators and structures by reducing the control actions.

This paper is organized as follows: The $50 \mathrm{MW} \mathrm{PTC}$ CSP dynamic model is briefly described in section 2 . The applied flow controller and defocus controller, GS-GPCs, are described in section 3 and section 4 . Section 5 describes the problematic of large scale plants through a simulation example. In section 6 the nonlinear optimization, observers and clustering are described. Results from simulations in different scenarios are presented in section 7 . Finally, in section 8, some concluding remarks are given.

\section{Parabolic trough field model}

This section describes the 50 MW plant used, (Sánchez et al., 2018a, 2019).

A nonlinear $50 \mathrm{MW}$ plant model is used for controller design and simulation purposes. To design the simulation nonlinear plant model and the observers, two types of mathematical models are used: a DPM is used for simulation purposes and a lumped parameter model. These models are used for simulation, controller design, estimation, and optimization. 


\section{Nomenclature}

A

$C(t, T) \quad$ Specific heat capacity $\left(\mathrm{J} /\left(\mathrm{kg}^{\circ} \mathrm{C}\right)\right)$

$C_{\text {loop }} \quad$ Loop heat capacity $\left(\mathrm{J} /{ }^{\circ} \mathrm{C}\right)$

$D$

G

$H_{l}(t, T)$

Hydraulic diameter of the pipe $(\mathrm{m})$

Collector aperture $(\mathrm{m})$

Thermal loss global coefficient

$\left(\mathrm{W} /\left(\mathrm{m}^{2} \mathrm{C}\right)\right)$

Metal-fluid heat transmission coefficient

$\left(\mathrm{W} /\left(\mathrm{m}^{2} \mathrm{C}\right)\right)$

$I(t) \quad$ Direct solar radiation $\left(\mathrm{W} / \mathrm{m}^{2}\right)$

$k(t, T) \quad$ Thermal conductivity $\left(\mathrm{W} /\left(\mathrm{m}^{\circ} \mathrm{C}\right)\right)$

$K_{\text {opt }} \quad$ Optical efficiency (Unitless)

$L \quad$ Length of pipeline $(\mathrm{m})$

$n_{o}(t) \quad$ Geometric efficiency (Unitless)

$\mathrm{Nu} \quad$ Nusselt number

$P \quad$ Power (MW)

$P_{c p}$

phi

$\operatorname{Pr}$

$Q(t)$
Fixed factor (loop geometrical and thermal properties $)\left(\mathrm{J} / \mathrm{m}^{3} \mathrm{C}\right)$

Fixed factor (Unitless)

Prandtl number

Solar field oil flow rate $\left(\mathrm{m}^{3} / \mathrm{h}, \mathrm{kg} / \mathrm{s}\right)$ $q(t)$

$q_{f f}$

Re

$S$

$t$

$T(x, t)$

$T_{a}(t)$

$T_{\text {in }}$

$T_{\text {out }}$

$T_{\text {mean }}$

$T_{\text {set-point }}$

$T_{r e f-C 4}$

$x$

$\Delta T$

$\mu(t, T)$

$\nu(t, T)$

$\rho(t, T)$
Loop oil flow rate $\left(\mathrm{m}^{3} / \mathrm{s}\right)$

Computed flow-rate by the

Feed Forward $\left(\mathrm{m}^{3} / \mathrm{s}\right)$

Reynolds number

Total reflective surface

Time (s)

Temperature $\left({ }^{\circ} \mathrm{C}\right)$

Ambient temperature $\left({ }^{\circ} \mathrm{C}\right)$

Inlet temperature $\left({ }^{\circ} \mathrm{C}\right)$

Outlet temperature $\left({ }^{\circ} \mathrm{C}\right)$

Mean temperature between inlet and outlet temperature $\left({ }^{\circ} \mathrm{C}\right)$

Temperature reference for tracking $\left({ }^{\circ} \mathrm{C}\right)$

Temperature set-point applied to the $4^{\text {th }}$ collector $\left({ }^{\circ} \mathrm{C}\right)$

Space $(\mathrm{m})$

Thermal difference $\left({ }^{\circ} \mathrm{C}\right)$

Dynamic viscosity of the fluid

$(\mathrm{Pa} \cdot \mathrm{s}=\mathrm{N} \cdot \mathrm{s} / \mathrm{m} 2=\mathrm{kg} /(\mathrm{m} \cdot \mathrm{s}))$

Kinematic viscosity $\left(\mathrm{m}^{2} / \mathrm{s}\right)$

Density $\left(\mathrm{kg} / \mathrm{m}^{3}\right)$

\subsection{Parabolic trough field}

A $50 \mathrm{MW}$ solar field extends throughout 110 hectares, approximately. Each loop has, typically, $4150 \mathrm{~m}$ collectors (total of $600 \mathrm{~m}$ approximately) (Guzmán, 2019; Helioenergy II, 2019; Solaben 2, 2019) with an approximate number of loops in the solar field of 90 (Guzmán, 2019; Helios I, 2019; Helioenergy II, 2019; Risca, 2019; Solnova 1, 2019). The plant model for this work is composed of 90 loops. Commercial plants have, generally, a north-south orientation for efficiency reasons.

Table 1

EuroTrough ET150 parameters.

\begin{tabular}{lll}
\hline Description & Value & Unit \\
\hline Focal length & 1.71 & $m$ \\
Aperture width & 5.77 & $m$ \\
Aperture area & 817.5 & $m^{2}$ \\
Number of Modules per Drive & 12 & Unitless \\
Length per Solar Collector Assembly (SCA) & 148.5 & $m$ \\
SCAs per loop & 4 & Unitless \\
Heat Collection Element (HCE) Type & Evacuated tube & Unitless \\
\hline
\end{tabular}

A solar parabolic trough plant can be described in terms of, collector (parameters, length and number collectors per loop), number of loops, receiver tube, heat transfer fluid characteristics and power cycle.

For the $50 \mathrm{MW}$ simulation plant the following elements have been selected:

1. Loop collector: EuroTrough ET150. Collector maximum reflectivity and parabolic shape index are assumed to be $0.91-0.92$ and 0.96 respectively. In Table 1 the main parameters of the EuroTrough ET150 collector are shown (Geyer et al., 2002; Kearney, 2007; System Advisor Model (SAM). NREL, 2018).

2. Receiver tube: Schott PTR70. This receiver has been commonly used in commercial solar plants (Andasol 1, 2019; Extresol-1, 2019; Ibersol Ciudad Real, 2019). This receiver tube has a length of $4060 \mathrm{~mm}$ at $20{ }^{\circ} \mathrm{C}$ ambient temperature with a borosilicate glass envelope with an outer diameter of $125 \mathrm{~mm}$. The metal pipe has an inner diameter of $66 \mathrm{~mm}$, an outer diameter of $70 \mathrm{~mm}$ and are made of steel-type DIN 
1.4541 or similar (Burkholder et al., 2007; SCHOTT Solar CSP GmbH, 2019). Maximum tube efficiency is assumed to be 0.91 .

3. Therminol VP1 as HTF. The operating range of this synthetic oil is $12-400{ }^{\circ} \mathrm{C}$ (Therminol VP1 HTF, 2019). Therminol VP1 degrades above $400^{\circ} \mathrm{C}$. HTF parameters approximation, such as fluid density $\left(\rho_{f}\right)$ and specific heat capacity $\left(C_{f}\right)$, are temperature dependent and can be obtained through equations (1) and (2). The reader should refer to the manufacturer, Therminol VP1 HTF (2019), for more parameters approximations.

$$
\begin{array}{r}
\rho_{f}=-0.90797 \cdot T+0.00078116 \cdot T^{2}-2.367 \times 10^{-6} \cdot T^{3} \\
+1083.25
\end{array}
$$

Nominal operation in this plants is typically reached when the inlet/outlet temperatures of the field are 293 and $393{ }^{\circ} \mathrm{C}$ approximately, with a thermal difference in the steam phase of $90-100{ }^{\circ} \mathrm{C}$. Rankine cycle has been assumed to be 0.381 (Andasol 1, 2019; Extresol-1, 2019)) in nominal operation. Assuming the plant is in perfect conditions the only losses in the steam phase will be produce by the parasitics effects. A typical value for this efficiency is 0.9 (System Advisor Model (SAM). NREL, 2018). Taking these parameters into account, under nominal operation, the maximum HTF flow used in the $50 \mathrm{MW}$ simulation model is $3000 \mathrm{~m}^{3} / \mathrm{h}$ approximately, equation 3, (Sánchez et al., 2018a, 2019).

$$
Q=\frac{P \cdot 10^{6}}{\Delta T \cdot C_{f} \cdot \mu_{\text {rankine }} \cdot \mu_{\text {parasitic }}}
$$

\subsection{Distributed parameter model}

The distributed solar field dynamics can be described by a partial differential equations (PDE) system shown in equation 4. The system energy balance is described in this set of PDEs (Carmona, 1985; Camacho et al., 1997):

$\rho_{m} C_{m} A_{m} \frac{\partial T_{m}}{\partial t}=I K_{o p t} n_{o} G-H_{l} G\left(T_{m}-T_{a}\right)-L H_{t}\left(T_{m}-T_{f}\right)$

$\rho_{f} C_{f} A_{f} \frac{\partial T_{f}}{\partial t}+\rho_{f} C_{f} q \frac{\partial T_{f}}{\partial x}=L H_{t}\left(T_{m}-T_{f}\right)$

Subindexes $f$ and $m$ are used referring to the fluid and metal. Geometric efficiency depends on declination, day of the year, local latitude, collector parameters, solar hour and hourly angle. Coefficients and parameters $H_{l}$, specific heat $C$ and density $\rho$ depends on the temperature of the fluid. Coefficient $H_{t}$ depends on fluid temperature and
HTF flow-rate (Camacho et al., 1997). An approximation for $H_{l}$ can be obtained from Burkholder et al. (2007), Lüpfert et al. (2008). To obtain $H_{t}$ value, equations (5) are used, where the dependency of the flow-rate can be observed (Sánchez et al., 2018a, 2019).

To discretize the system, the receiver tube longitudinal dimension is used, obtaining a set of sub-systems. In this way, the model is simulated, to obtain the dynamics of the loops, by using a chain of sub-models. Each loop has been divided into 300 segments ( $2 \mathrm{~m}$ each) to provide a good simulation performance of the temperature evolution (Sánchez et al., 2018a, 2019).

$$
\begin{aligned}
& R e=Q \cdot D /(\nu \cdot A) \\
& \operatorname{Pr}=C_{f} \cdot \mu / k \\
& N u=0.025 \cdot\left(\operatorname{Re}^{0.79}\right) \cdot\left(\operatorname{Pr}^{0.42}\right) \cdot p h i \\
& H_{t}=N u \cdot k / D
\end{aligned}
$$

\subsection{Concentrated parameter model}

The concentrated parameter model (CPM) is a simplification of the spatially distributed solar field. This simplification provides an overall description of the solar field in terms of the fluid internal energy variation by equation 6. This model is used to obtain a reflectivity estimation and to design the Feed Forward control action (Sánchez et al., 2018a).

$$
\begin{array}{r}
C_{\text {loop }} \frac{d T_{\text {out }}}{d t}=K_{\text {opt }} n_{o} S I-q P_{c p}\left(T_{\text {out }}-T_{\text {in }}\right) \\
-H_{l} S\left(T_{\text {mean }}-T_{a}\right)
\end{array}
$$

where $P_{c p}$ is approximated by $1.868 \times 10^{6} \mathrm{~J} / \mathrm{m}^{3} \mathrm{C}, C_{l o o p}$ is approximated by $3.287 \times 10^{6} \mathrm{~J} /{ }^{\circ} \mathrm{C}$ and $S$ is equal to $3427 \mathrm{~m}^{2}$.

\section{Flow-Rate MPC control scheme}

This section describes the flow-rate MPC control strategy used for field outlet temperature tracking. A GS-GPC is used to control the HTF flow-rate, (Sánchez et al., 2018a, 2019). This control strategy is based on global dynamic linear models of the solar field. GS-GPC controller has already shown to have a good performance in temperature tracking and disturbance rejection.

\subsection{Generalized Predictive Control}

The GPC algorithm is based on the following singleinput single-output model (Camacho and Bordons, 2007):

$$
A\left(z^{-1}\right) y_{k}=z^{-d} B\left(z^{-1}\right) u_{k-1}+\frac{C\left(z^{-1}\right)}{\Delta} e_{k}
$$

where $u_{k}$ and $y_{k}$ are the control and output sequences of the plant, $e_{k}$ is a zero mean white noise term and $\Delta$ is the integrator operator. $A, B$ and $C$ are polynomials in the backward shift operator $z^{-1}$ : 


$$
\begin{aligned}
& A\left(z^{-1}\right)=1+a_{1} z^{-1}+\ldots+a_{n a} z^{-n a} \\
& B\left(z^{-1}\right)=b_{0}+b_{1} z^{-1}+\ldots+b_{n b} z^{-n b} \\
& C\left(z^{-1}\right)=1+c_{1} z^{-1}+\ldots+c_{n c} z^{-n c}
\end{aligned}
$$

where $d$ is the dead time of the system and $\Delta$ is the operator $1-z^{-1}$. This model is known as a Controller AutoRegressive Integrated Moving-Average (CARIMA) model. Consider a multistage cost function of the form:

$$
\begin{array}{r}
J\left(N_{1}, N_{2}, N_{u}\right)=\sum_{j=N_{1}}^{N_{2}} \delta(j)[\hat{y}(k+j \mid k)-w(k+j)]^{2} \\
+\sum_{j=1}^{N_{u}} \lambda(j)[\Delta u(k+j-1)]^{2}
\end{array}
$$

where $\hat{y}(k+j \mid k)$ is an optimum $\mathrm{j}$ step ahead prediction of the system output, $N_{1}$ and $N_{2}$ are the minimum and maximum costing horizons, $N_{u}$ is the control horizon, $\delta(j)$ and $\lambda(j)$ are weighting sequences and $w(k+j)$ is the future reference trajectory. The aim of GPC is to minimise $J\left(N_{1}, N_{2}, N_{u}\right)$ in order to compute a future sequence of control actions $u(k), u(k+1), \ldots$ that drives the future plant output $y(k+j)$ close towards $w(k+j)$.

Hence given a CARIMA plant model and suitable cost function, the minimum of the cost function can be obtained by setting the gradient of $\mathbf{J}$ equal to zero and solving the control sequence $\Delta \mathbf{u}$ by the following equation (Camacho and Bordons, 2007):

$$
\Delta \mathbf{u}=\left(\mathbf{G G}^{T}+\lambda \mathbf{I}\right)^{-1} \mathbf{G}^{T}(\mathbf{w}-\mathbf{f})
$$

where matrix $\mathbf{G}$ contains the step response coefficients of the forced response model (Camacho et al., 2012), I is the eye matrix, $\mathbf{f}$ is the free response of the plant, $\mathbf{w}$ is the future reference trajectory vector and $\lambda$ is the control weighting vector (Camacho and Bordons, 2007).

\subsection{Gain scheduling and Feedforward control}

The design of a GS-GPC is described in Camacho et al. (1994, 1997), Camacho and Bordons (2007). The GS-GPC strategy is used in conjunction with a series FF controller due to its effectiveness at rejecting measurable disturbances (Camacho et al., 1997) and contribution in preserving the validity of the linear description assumption of the plant throughout the operation flow range.

HTF flow-rate is the main variable dictating the plant dynamics. To cover the operation range, the GS-GPC is based on linear models that have been identified at four different flow-rates operating points (1494, 1908, 2322 and $2736 \mathrm{~m}^{3} / \mathrm{h}$ ), see Fig. 1, (Sánchez et al., 2018a, 2019). These linear models describe the global dynamics of the plant.

The FF is computed using equation (10) which is obtained from the CPM description (Camacho et al., 1992), equation (6). The output of the FF is the fluid flow, $q_{f f}$.

$$
q_{f f}=\frac{K_{o p t} n_{o} S I-H_{l} S\left(T_{m e a n}-T_{a}\right)}{P_{c p}\left(T_{r e f}-T_{i n}\right)}
$$

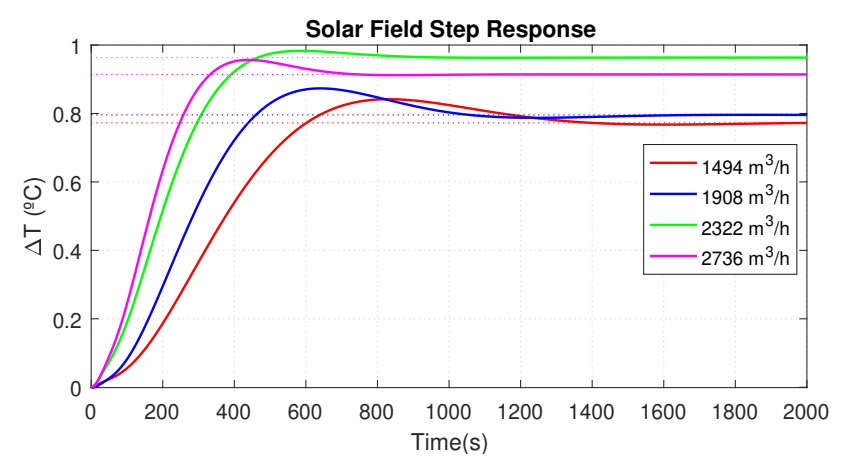

Figure 1 Step response of the solar field linear models.

The control scheme, see Fig. 2, works as follows: The GS-GPC receives the temperature set-point for the solar field and the current mean temperature and computes a virtual reference temperature, $T_{\text {ref }}$, for the FF. The FF computes the HTF flow-rate taking into account the measurable disturbances, the virtual reference and the mean temperature of the equivalent loop to track the temperature set-point at steady state.. Since the GS-GPC + FF scheme is considering a global model by one loop, the calculated flow-rate is for one loop. If the models where completely perfect, the virtual reference computed by the GS-GPC would be the same as the desired set-point for the outlet temperature of the field. The GS-GPC + FF scheme is presented in Fig. 2 where $Q_{f f}$ represents the global flow-rate (equal to $q_{f f} \cdot N$, where $N=90$ loops) for the complete field and $Q$ is the measured flow-rate (Sánchez et al., 2018a, 2019).

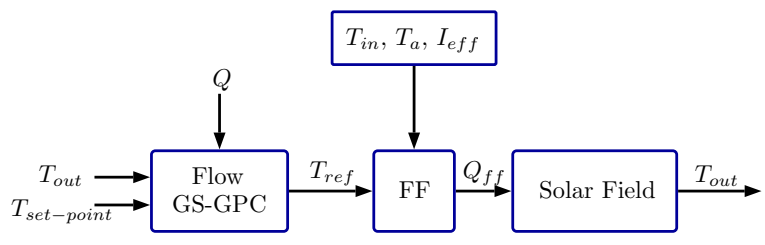

Figure 2 GS-GPC + FeedForward control scheme.

\section{Collector defocus MPC}

Commercial CSPs are, generally, oversized to produce a certain amount of energy throughout the year. This means that at certain periods of the year, such as in summer, the amount of energy that reaches the solar field is too much to be processed by the plant. This causes the field to overheat since it is not possible to increment the flow-rate as much as it should be needed. To prevent overheating and therefore the degradation of the HTF (around $400{ }^{\circ} \mathrm{C}$ ), commercial plants have a safety mechanism based 
on defocusing the collectors (sun-tracking angle modification). When a collector is taken out of focus, it receives less energy and therefore the HTF will not get overheated. This mechanism is generally applied to the fourth collector in a heuristic manner based on outlet temperature thresholds. However, using a threshold based control may cause undesired oscillations in the field temperature.

In normal operation, the fourth collector defocus control is enough to prevent the oil temperature from exceeding the manufacturer recommended safety limits. However, in cases of power limitation, it may be necessary to include the defocus in other collectors. In a previous work, (Sánchez et al., 2018a), a GS-GPC controller was designed for the third and fourth collector defocus, showing good temperature reference tracking results. This controller was based on a defocus curve with a very non-linear behavior, see Fig. 3, (Goswami et al., 2000). As can be seen in Fig. 3 , the curve has a greater slope around 2-3 defocus degrees while it is much smoother in the $0-1$ and $4-5$ defocus degrees areas. In the zone of 3-5 defocus degrees, it can be observed that the efficiency quickly approaches zero, which implies very little control authority. Since the function is non-linear, the gain-scheduling is designed at 9 different points of defocus angle $(0.5,1,1.5,2,2.5,3,3.5,4$ and 4.5 degrees). From a certain defocus angle, efficiency begins to decrease rapidly, since rays no longer reach the tube. Moreover, the plant responds differently depending on the flow-rate, so defocus linear models will not be the same for all flow-rates. To improve the performance of collector defocus GS-GPC, 9 linear models are obtained for each of the flow-rate points where Flow GS-GPC has been designed $\left(1494,1908,2322\right.$ and $\left.2736 \mathrm{~m}^{3} / \mathrm{h}\right)$. In this way the linear models for the defocus GS-GPC control will cover the operation range. The linear models to implement the defocus GS-GPC are presented in Sánchez et al. (2018a). In this work, this defocus GS-GPC controller is used with a high and fixed temperature set-point $\left(396{ }^{\circ} \mathrm{C}\right)$. A complete explanation of the defocus GS-GPC control design can be found in (Sánchez et al., 2018a).

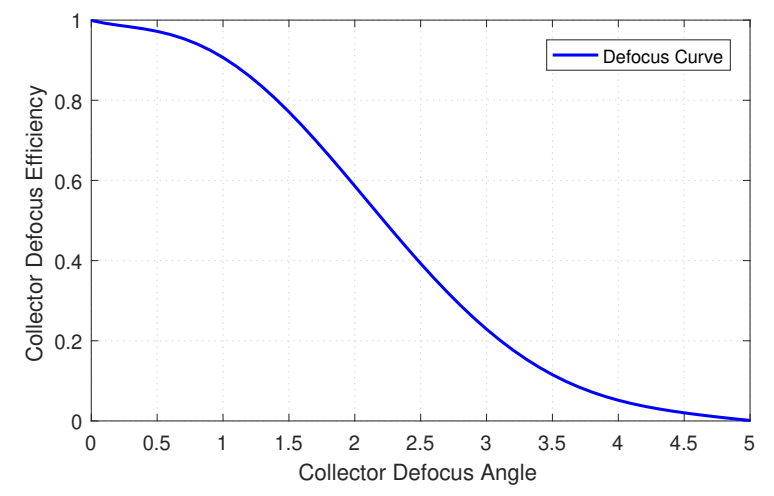

Figure 3 Collector efficiency-defocus angle curve.

\section{Large scale parabolic trough plant problematic}

Commercial solar plants occupy large areas to house the solar field formed by the collectors, piping system and the steam generator. As an example, Solaben $50 \mathrm{MW}$ plants occupy 110 hectares with a solar field of 90 loops and 360 collectors (Helioenergy II, 2019, Solaben 2, 2019)). Given this amount of loops (and collectors), the optical efficiency may not be the same in the whole field. Due to this difference in the efficiencies, a certain number of loops will be at a lower temperature due to lower efficiency while another amount of loops will be at a higher temperature at their outlet. However, the temperature tracking control is applied at the outlet temperature of the solar field since this temperature will eventually be the oil temperature at the inlet of the steam generator. Given the dimensions of these plants, approximating the solar field by an average loop may not be efficient. This issue is even more important in bigger plants such as Solana (280 MW, 800 hectares) (Helioenergy II, 2019, Solana Generating Station, 2019). Optical efficiency depends, among others, on the following:

1. Reflectivity, related to the cleanliness of the reflecting surfaces.

2. Efficiency of the tube related to the cleaning status and the structural state of the receiver tube.

3. Condensation, related to atmospheric conditions.

4. Shape factor, related to the structural state of the collector/loop.

5. State of flexible hoses, related to the structural state of the collector/loop.

In periods of the year in which the plant works at saturation (maximum flow-rate and electric power production), it is easy to find situations in which part of the field is much warmer than others due to what has been previously mentioned. Generally, this can occur in part of spring and autumn as well as throughout the summer. In these cases, even if the plant continues to produce maximum electric power, a part of the field will be defocused since the received solar energy may be too high for the steam generator and turbine. As mentioned, the defocus algorithm is a type of security control, not a specific control to regulate the outlet temperature. The defocus algorithm usually implements a series of thresholds modulating the defocusing angles depending of the current outlet temperature. This type of control produces high oscillations. That is why whenever possible, its use should be minimized.

A simulation showing this effect is presented in Figs. 4 and 5 . Table 2 shows the reflectivity ranges of the loops. In Fig. 4 the temperatures and defocus angles of each of the 90 loops are shown. The disparity in the outlet temperatures of the loops is observed due to the different efficiencies. This will cause the loops with higher efficiency to be defocused in order to maintain safe loop temperatures.

Fig. 5 shows how the global flow-rate controller (GSGPC) is trying to control the field outlet temperature. 

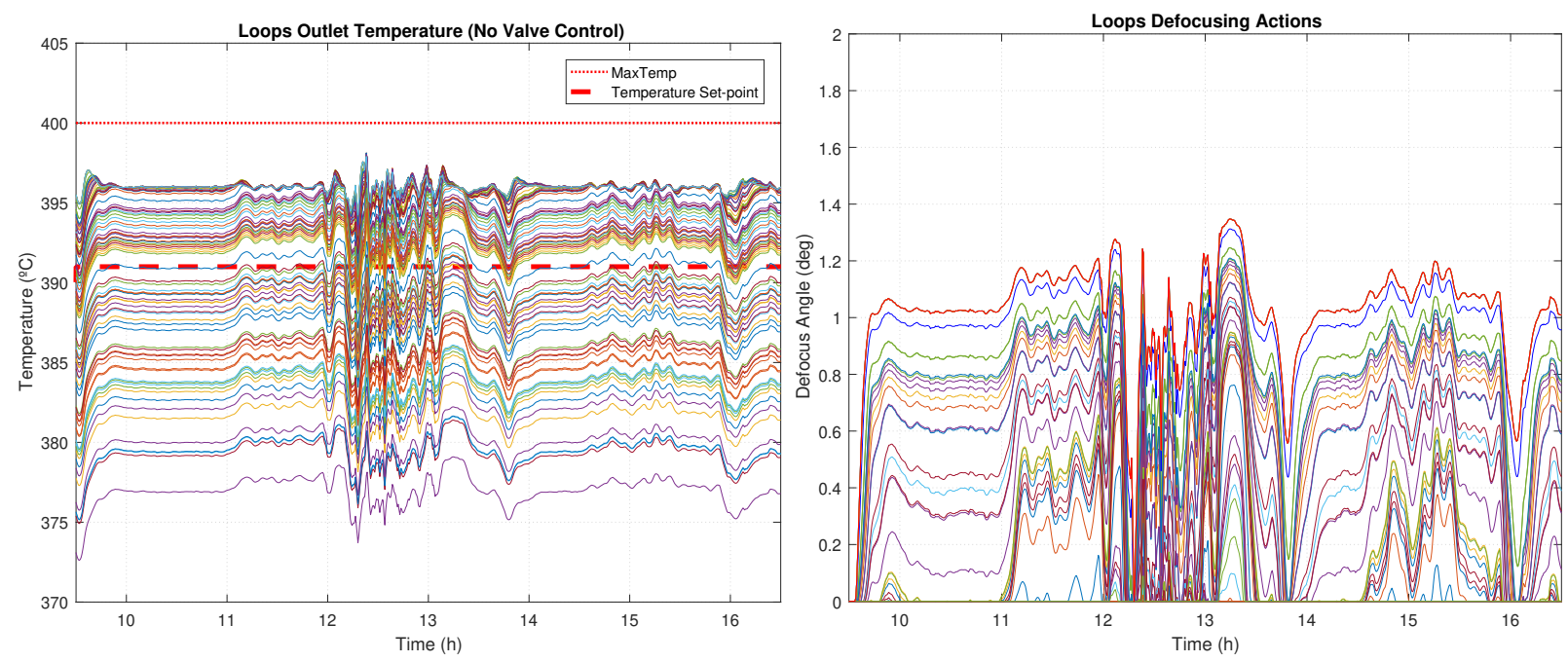

Figure 4 Loops temperatures (left) and defocus angles (right) when there is no valve control under stable radiation.

Table 2

Reflectivity ranges and Loops

\begin{tabular}{lc}
\hline Reflectivity Range & Loops Number \\
\hline $0.74-0.75$ & 4 \\
\hline $0.75-0.77$ & 67818 \\
\hline $0.77-0.79$ & 31115 \\
\hline $0.79-0.81$ & 2591013192023 \\
\hline $0.81-0.83$ & 121416222428 \\
\hline $0.83-0.85$ & 212526273031323435384344 \\
\hline $0.85-0.87$ & 333637424550526872 \\
\hline $0.87-0.89$ & 414648495558606263798189 \\
\hline $0.89-0.90$ & 29515759707378808284 \\
\hline $0.90-0.91$ & 53566465666774767788 \\
\hline $0.91-0.92$ & 4754616971758385868790 \\
\hline
\end{tabular}
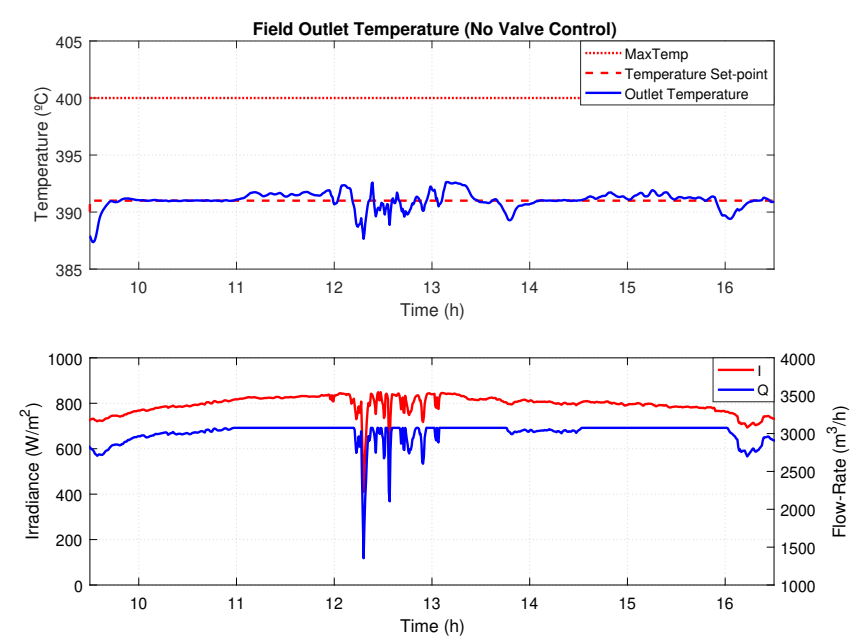

Figure 5 Field outlet temperature (top) and field flow-rate/irradiance (bottom) (No valve control applied)

Achieving a good tracking of the set-point temperature $\left(391{ }^{\circ} \mathrm{C}\right)$ until 11 am. At this time, the controller is applying the maximum available flow-rate to the plant and has lost its control authority. It is when the defocus control will begin to carry out its safety correcting actions to prevent the hottest loops from exceeding oil degradation temperatures.

Although this situation is not critically dangerous, it is possible to avoid it to a greater extent by improving the thermal balance. The thermal balance using the proposed strategy in this paper will increment the flow-rate and cool down the hottest loops to avoid unnecesary defocus actions and a decrease the HTF flow of the coldest loops to warm them up.

\section{Optimization for field thermal balance}

The objective of the non-linear optimization is to obtain the values of the apertures of the valves of the loops, which make the field as homogeneous as possible with respect to the outlet temperature of the loops. Subsections 6.1 and 6.2 describes briefly the UKF used to estimate the non-measurables states of the loops and the lumped parameter model used to estimate the loops efficiencies. The valve control and the computation times analysis are presented in 6.3. Finally, in subsection 6.4 the loops clustering is proposed to reduce the number of control variables.

\subsection{Nonlinear state estimator: the unscented Kalman fil- ter}

The Unscented Kalman Filter (UKF) has been proposed in the literature as a way to reduce the errors introduced by the linearization performed by the Extended Kalman Filter (EKF) (Simon, 2006).

Lets assume the following set of nonlinear systems:

$$
\begin{aligned}
& x_{k+1}=G\left(x_{k}, u_{k}, n_{k}\right) \\
& y_{k}=F\left(x_{k}, v_{k}\right)
\end{aligned}
$$

where $x_{k}$ is the non-observable state space vector, $y_{k}$ is the measured observation and $u_{k}$ is the input to the 
system. Functions $G$ and $F$ are nonlinear functions and are assumed to be known. $n_{k}$ and $v_{k}$ are the process noise and the observation noise.

The UKF does not approximate the nonlinear functions $G$ and $F$, as the EKF does, but approximates the probability density function by a Gaussian. This is represented deterministically by samples (known as $\sigma$-points or sigma points), chosen appropriately, which capture the covariance and mean of the Gaussian probability density function. The UKF uses the unscented transformation (UT) (Romanenko and Castro, 2004; St-Pierre and Gringras, 2004) to capture the covariance and mean of the system. The UT is a method to calculate the statistics of a random variable which undergoes a non-linear transformation Haykin (2001). Subsequently, the $\sigma$-points are propagated through the nonlinear functions $G$ and $F$. Various variations and improvements have been proposed since the original UKF was proposed, e.g, an improvement on the unscented transformation was presented in Wang et al. (2017). In this work, authors proposed the incorporation of random parameters into the state vector in order to get a higher number of sigma points.

For this work, the UKF is used to estimate the internal temperatures of the loops. That is, the temperatures of the fluid and metal of the segments in which the loops are divided. The UKF has already been used to obtain estimations of the effective solar irradiance and loops internal temperatures of a solar plant showing good results (Gallego and Camacho, 2012; Sánchez et al., 2019). Since the UKF works with a nonlinear model, the model described by the equations (4) is used but with a simplification. Instead of 300 segments, as in the simulation model, 80 segments will be used. In this way the complexity of the estimator can be reduced since a large number of tube segments implies a large number of parameters in the covariance matrices needed to be adjusted (Gallego and Camacho, 2012). Since the nonlinear model also uses the optical efficiency parameter, to obtain better results in the estimation of the internal temperatures of the loop, an estimation of the reflectivity of the loops is obtained. The following subsection describes the estimation of the reflectivity.

\subsection{CPM collector efficiency estimation}

As commented, not all loops have the same optical efficiency due to multiple causes such as dust, wind etc. An estimation of this parameter is needed not only by the nonlinear optimization algorithm but by the UKF for estimating the non-measurable states. The overall optical efficiency can be obtained using the concentrated parameter model equation (12) as follows:

$K_{\text {opt }}=\frac{C_{\text {loop }} \frac{d T_{\text {out }}}{d t}+q P_{c p}\left(T_{\text {out }}-T_{\text {in }}\right)+H_{l} S\left(T_{\text {mean }}-T_{a}\right)}{n_{o} S I}$
The variation of the reflectivity along the day is slow which means a quasi-static characteristic. Due to the nature of the concentrated parameter model, the obtained result is filtered to smooth possible abrupt changes in the reflectivity estimation. The estimation of the optical efficiency is obtained using the concentrated parameters model in periods in which the plant is in steady state conditions. It is done continuously to be able to capture small (or high) variations in the collector's efficiency due to environmental conditions along the day. The applied filter is a first order filter with a $\tau=300 \mathrm{~s}$ to avoid sudden changes that could appear in the measured variables.

\subsection{Inlet valves control}

The objective of the non-linear optimization is to obtain the values of the manipulated variables, apertures of the loops inlet valves, which make the field as homogeneous as possible with respect to the outlet temperature of the loops. Improving the thermal balance of the solar field avoids thermal energy losses produced by defocus actions. The general formulation of the nonlinear problem is presented in equation (13).

$$
\begin{aligned}
\min J & =\sum_{n=1}^{N_{L} \text { oop }}\left(\sum_{j=N_{1}}^{N_{2}} \delta(j)\left[\hat{y_{n}}(t+j \mid t)-w(t+j)\right]^{2}\right. \\
& \left.+\sum_{j=1}^{N_{u}} \lambda(j)\left[\Delta u_{n}(t+j-1)\right]^{2}\right) \\
\text { s.t }: & \\
& U_{\min }<U(t+j)<U_{\max } \\
& \Delta u_{\min }<\Delta u(t+j)<\Delta u_{\max } \\
& x=g(x, U), y=f(x)
\end{aligned}
$$

where $\hat{y_{n}}(t+j \mid t)$ is an optimum $\mathrm{j}$ step ahead prediction of the system output, $N_{L}$ oop is the number of loops, $N_{u}$ is the control horizon, $\delta(j)$ and $\lambda(j)$ are weighting sequences and $w(t+j)$ is the future reference trajectory (setpoint). Regarding the constraints, $U_{\min }$ and $U_{\max }$ are the minimum and maximum control signals while $\Delta u_{\text {min }}$ and $\Delta u_{\max }$ are the minimum and maximum control signals increments.

In the case addressed in this strategy, the main objective is not to track a given reference because this is performed by the main flow controller. The aim is minimizing the difference among the outlet temperatures of the loops in steady state. By minimizing those distances, the outlet temperatures of all loops become closer and the thermal disparity is minimized.

The resolution of the problem involves the simulation of the evolution of the field temperature, that is, the temperature of the loops along the prediction horizon. For this, the DPM is used. As mentioned above, in the section 6.1, a model divided into 80 pieces has been used. The valves values do not change throughout the prediction horizon, 
because the goal is to compute only one control action for each valve to achieve a thermal balance of the field in steady state. The reason to do this is that possible coupling between the valve and flow controllers is not desirable and may cause an oscillatory behavior. The intermediate evolution of the outlet temperature is not penalized in the cost function.

The only constraint for this optimization is the minimum and maximum value for the valves apertures, $U_{\min }<$ $U(t+j)<U_{\max }$. Considering that only the outlet temperature of the loops at the end of the prediction horizon are used to compute the cost function, the proposed nonlinear optimization problem can be posed as follows (14):

$$
\begin{gathered}
\min J=\sum_{m=1}^{N_{\text {Loop }}} \sum_{n=1}^{N_{\text {Loop }}}\left|\hat{y_{m}}\left(N_{2}\right)-\hat{y_{n}}\left(N_{2}\right)\right| \\
\text { s.t : } \\
\quad U_{\min }<U(t+j)<U_{\max } \\
x=f(x, U), y=g(x)
\end{gathered}
$$

It has to be noted that the optimization problem receives the flow-rate (since it is needed to compute the evolution of the loops) but it does not change it.
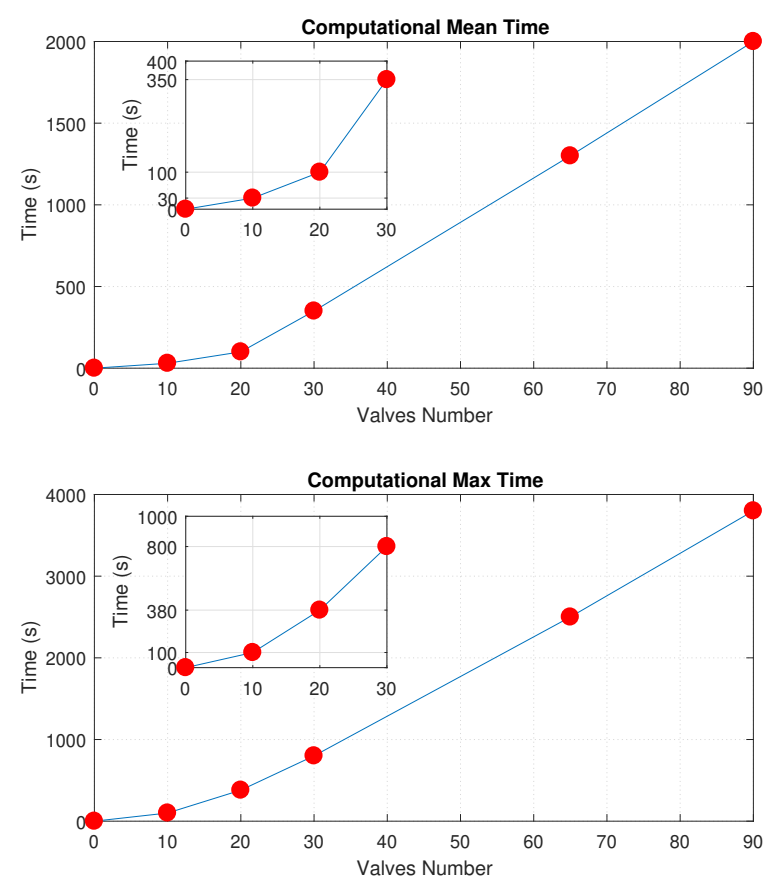

Figure 6 Optimization computation times depending on the number of the decision variables.

The optimization problem is computed every 30 minutes. This sampling time has threefold objectives: i) avoid interaction between the GS-GPC flow controller (sampling time of 30 seconds) and the valve controller (sampling time of 30 minutes) which can be harmful; ii) provide sufficient time to the nonlinear optimization algorithm to reach a proper solution and iii) to wait until steady state conditions are reached to assure that transport delays do not affect to the disparity of temperatures at the outlet of the loops. For this work, it has been assumed that the inlet valves aperture precision is $1 \%$.

Trying to optimize a nonlinear problem with 90 decision variables may be computationally demanding. In fact, the time needed for its computation may be greater than the control sampling time for the valve controller. Several simulations have been performed for different number of decision variables (valves), in order to check the time needed to reach a reasonable solution. Matlab 2016b optimization toolbox was used to solve this optimization problem on a $3.6 \mathrm{GHz}$, i7 processor and $12 \mathrm{~GB}$ of RAM PC. In Fig. 6, the maximum and mean time obtained are shown. The maximum time shown refers to the time needed to obtain results when the plant is far from the optimal solution. In this case it has been obtained by placing all the valves at a $100 \%$ aperture. The mean time is the computing time needed when the plant is close, or at least, not far from an optimal solution.

Solving the problem with 10, 20 or 30 variables (valves) is feasible, less than 30 minutes both the mean and the maximum. For a larger number of variables the problem would need larger computational times. In fact, solving the problem for 90 valves would require an average of 2000 seconds.

Although the time shown may vary depending on the algorithm used, hardware and specifications, it gives an idea of the number of control variables that can be applied to solve the optimization process in the proposed times. To solve the thermal balance optimization within the proposed time, a reduction in the number of variables is needed. The solution proposed in this paper is grouping loops of similar efficiency using a clustering algorithm. The selected algorithm to obtain the clusters is k-means which is detailed in the following section. The hydraulic system has been assumed to be linear. Although this system will modify the flow-rate on every loop when a valve is changed it has been assumed to be linear to simplify the optimization problem. Including the hydraulic model in the optimization problem would provide a more realistic scenario but at the cost of increasing the complexity of the problem a lot. Considering the hydraulic model will actually enlarge these optimization times. This paper intends to be a starting point in the solution of a problem which affect the operation of large scale solar plant.

The non-linear optimization problem has been programmed using the Matlab function fmincon. The computation of the optimization problem, which tries to minimize the cost function given by the Eq. (14), has the structure detailed in Algorithm (1). The optimization process begins with the clustering of loops to generate groups of loops with similar properties. Grouping the loops will reduce the optimization process computation times in two 
ways: (i) reducing the number of decision variables reduces the searching space and thus the computation time and (ii) the optimization problem needs to simulate the evolution of the loops temperatures along a prediction horizon, therefore, reducing the number of loops to be simulated will reduce the amount of time needed to simulate the solar field. Since the loops are being grouped, virtual loops have to be created. These virtual loops will represent the loops groups. The parameters and variables of the virtual loops, for the optimization problem, will be the averaged values of the loops that make up each group. For example, the efficiency of the virtual loop will be the average of the estimations of the efficiencies of the loops that belong to a group, which have been obtained with the CPM observer. Likewise, the states of the virtual loops (segments temperatures) will be the averaged values of the temperatures of the segments of the loops that form each cluster. The simulation of the virtual loops along the horizon of prediction will be performed for given values of the valve apertures. Once the virtual loops have been dynamically simulated for these valve openings, the cost function is calculated. If the cost function obtained value is minimum, the process is completed. If this is not the case, the process of selecting different valves apertures (which is carried out by the fmincon function) and virtual loops simulation is computed once more.

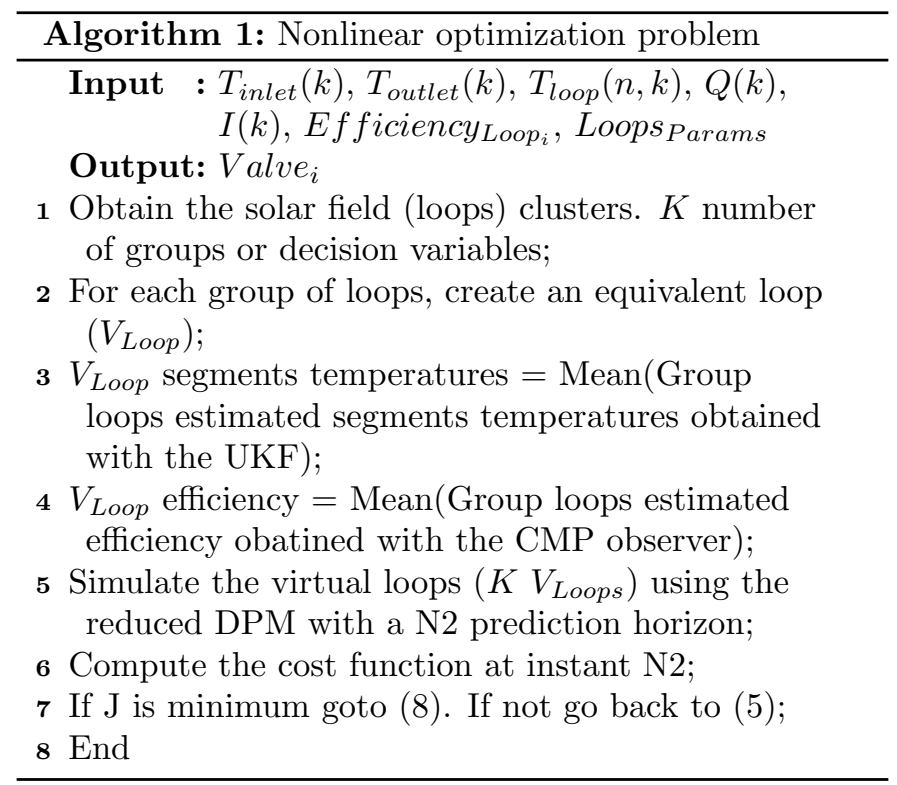

\subsection{K-Means loops clustering}

The objective of a cluster analysis is to carry out a division of a data set into blocks or clusters containing elements similar to each other. One of the most popular clustering methods is K-means. The goal is to find $\mathrm{K}$ points called centroids of the clusters. The data will be grouped to maximize the similarity between the data points and the associated centroids. A data point is con- sidered to be in a particular cluster if it is closer to that cluster's centroid than any other centroid.

The classical method uses an iterative heuristic technique by means of which the centroids of the clusters are obtained, known as Lloyd's algorithm (Lloyd, 1982). KMeans finds the best centroids by the following steps:

1. Obtain an initial set of $\mathrm{k}$ means $c_{1}(1), \ldots, c_{k}(1)$ randomly.

2. Data assignment step: Each observation is assigned to the cluster with the least squared Euclidean distance with respect to the mean.

$$
\begin{aligned}
S_{i}^{(t)}= & \left\{x_{p}:\left\|x_{p}-c_{i}^{(t)}\right\|^{2} \leq\left\|x_{p}-c_{j}^{(t)}\right\|^{2}\right. \\
& \forall j, 1 \leq j \leq k\}
\end{aligned}
$$

Notice that $x_{p}$ may be assigned to several clusters, $S^{(t)}$, but it will only be assign to one cluster, $S^{(t)}$.

3. Update step of the centroids: New means are computed. These new values will be the be the centroids of the observations in the new clusters.

$$
c_{i}^{(t+1)}=\frac{1}{\left|S_{i}^{(t)}\right|} \sum_{x_{j} \in S_{i}^{(t)}} x_{j}
$$

where $\left|S_{i}^{(t)}\right|$ is the number of points assigned to the cluster $i$.

4. Repeat steps 2 and 3 until convergence is achieved. Convergence will be reached when the assignments (step 2) no longer change.

For the case of the solar plant, the main variables to cluster the loops are the loop outlet temperature and the estimated efficiency. Fig. 7 shows the groups by colours in which the 90 loops, with the reflectivity ranges shown in Table 2, have been clustered. The members of each cluster are detailed in Table 3 .

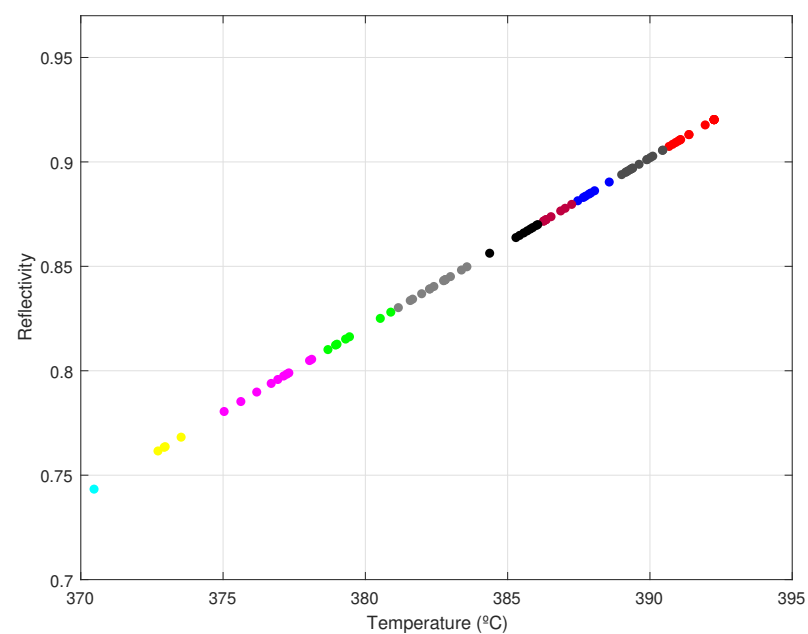

Figure 7 Example 1: Clustering result (10 groups) for 90 loops when loops are not defocusing 
Table 3

Clusters and Loop members

\begin{tabular}{lc}
\hline Valve Group & Loops Number \\
\hline 1 & 69758385868790 \\
\hline 2 & 29121416222328 \\
\hline 3 & 404855606263798189 \\
\hline 4 & 4 \\
\hline 5 & 11721242526273031323435384344 \\
\hline 6 & 367818 \\
\hline 7 & 2951565759707374767778808284 \\
\hline 8 & 5336373941424546495052586872 \\
\hline 9 & 47535461646566677188 \\
\hline 10 &
\end{tabular}

However, in order to obtain a robust clustering, the defocus angle applied to every loop is also taken into account in the Euclidian distance calculation by the clustering technique.

This helps to discriminate better if several loops have a similar outlet temperature and a similar estimated efficiency but may be defocusing with different angles. These loops can be grouped in the same cluster.

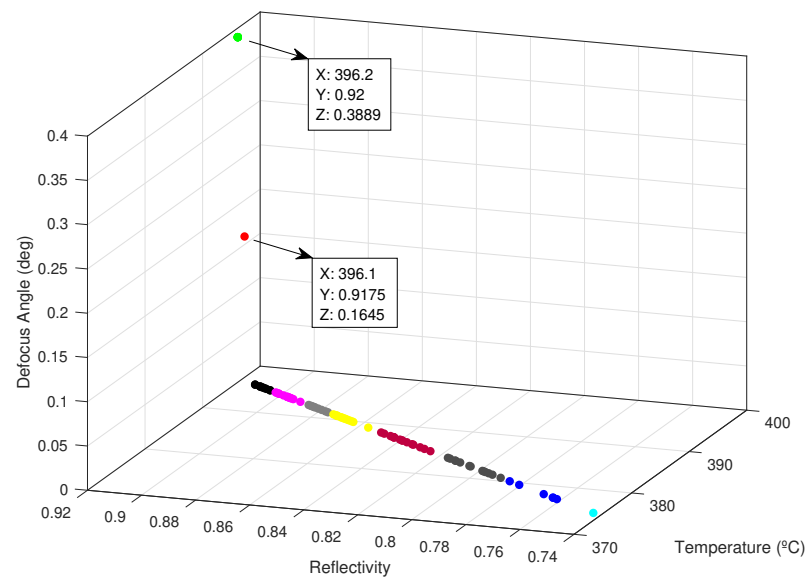

Figure 8 Example 2: Clustering result (10 groups) for 90 loops when there are loops defocusing

Fig. 8 shows the clustering (10 groups) of 90 loops in which there are two groups of loops which have approximately the same temperature and estimated reflectivity but the defocus angle is different. These groups are included in two different clusters.

\section{Results}

In this section, results from simulations are presented.

In the first simulation case, the plant is affect by a stable radiation levels. The proposed strategy is tested with 10 and 20 decision variables (valves). The valves are grouped using the above-mentioned k-means clustering algorithm. Both scenarios have been graphically and numerically compared to the case presented in section 5 where no valve control was considered. A second case is presented showing results in situations of medium but continuous irradiance transients.

The first case is presented in Figs. 9, 10, 11, 12 and 13 for which a high reference temperature has been used, 391 ${ }^{\circ} \mathrm{C}$.

Through the proposed strategy using clustering of 10 decision variables (valves), it can be observed how the effect of acting on the valves achieves a thermal equilibrium of the field as seen in Fig. 10. The loops are concentrated in a much narrow range than the case without valve control, Fig. 4. It can also be observed how the defocusing actions have diminished to a great extent compared to that of Fig. 4 since the temperatures are now more homogeneous. An average temperature difference of $20^{\circ} \mathrm{C}$ is reduced to a $4^{\circ} \mathrm{C}$ approximately.
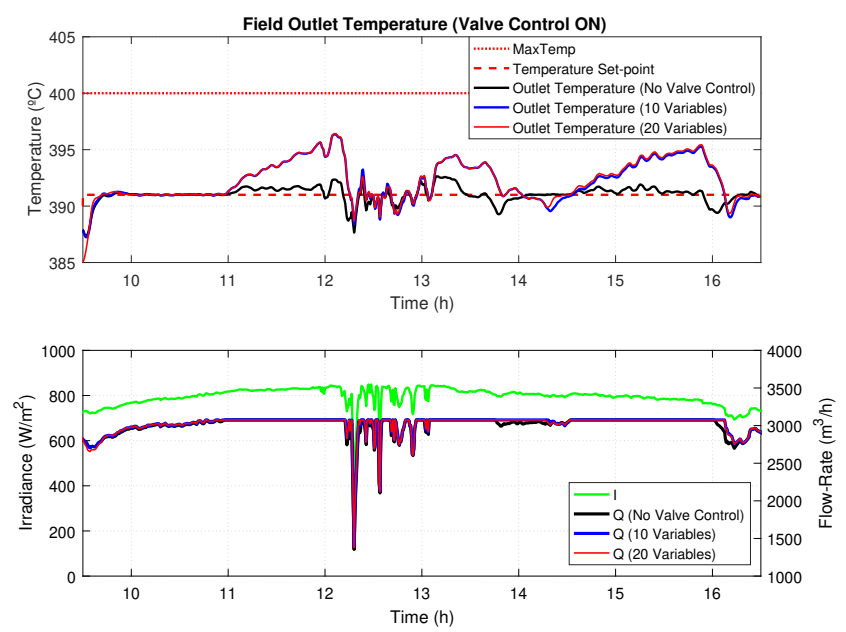

Figure 9 Field outlet temperature (top) and flow-rate (bottom) comparison with stable radiation.

Results when 20 decision variables are applied, see Fig. 10, are similar to the obtained with 10 variables, although in this case the defocus actions are somewhat smaller. Since there is a greater number of valves to balance the field, a finer adjustment can be obtained and therefore remove some defocus actions.

It is possible to verify that this technique does not affect the performance of the field, referring to Fig. 9 where the flow-rate and field outlet temperatures of each of the 3 simulations are compared. When the valve control is applied, the outlet temperature is even higher than when it is not, and the flow-rate remains the same since the plant is in saturation. That is to say, the plant is actually at a higher saturation level than what it looked like but also the number of defocus actions made on the loops is decreasing. In this case, the obtained average temperature difference has been decreased to a value of $2.4^{\circ} \mathrm{C}$ approximately.

The actions on the different groups of valves are shown in Figs. 11 and 12. 

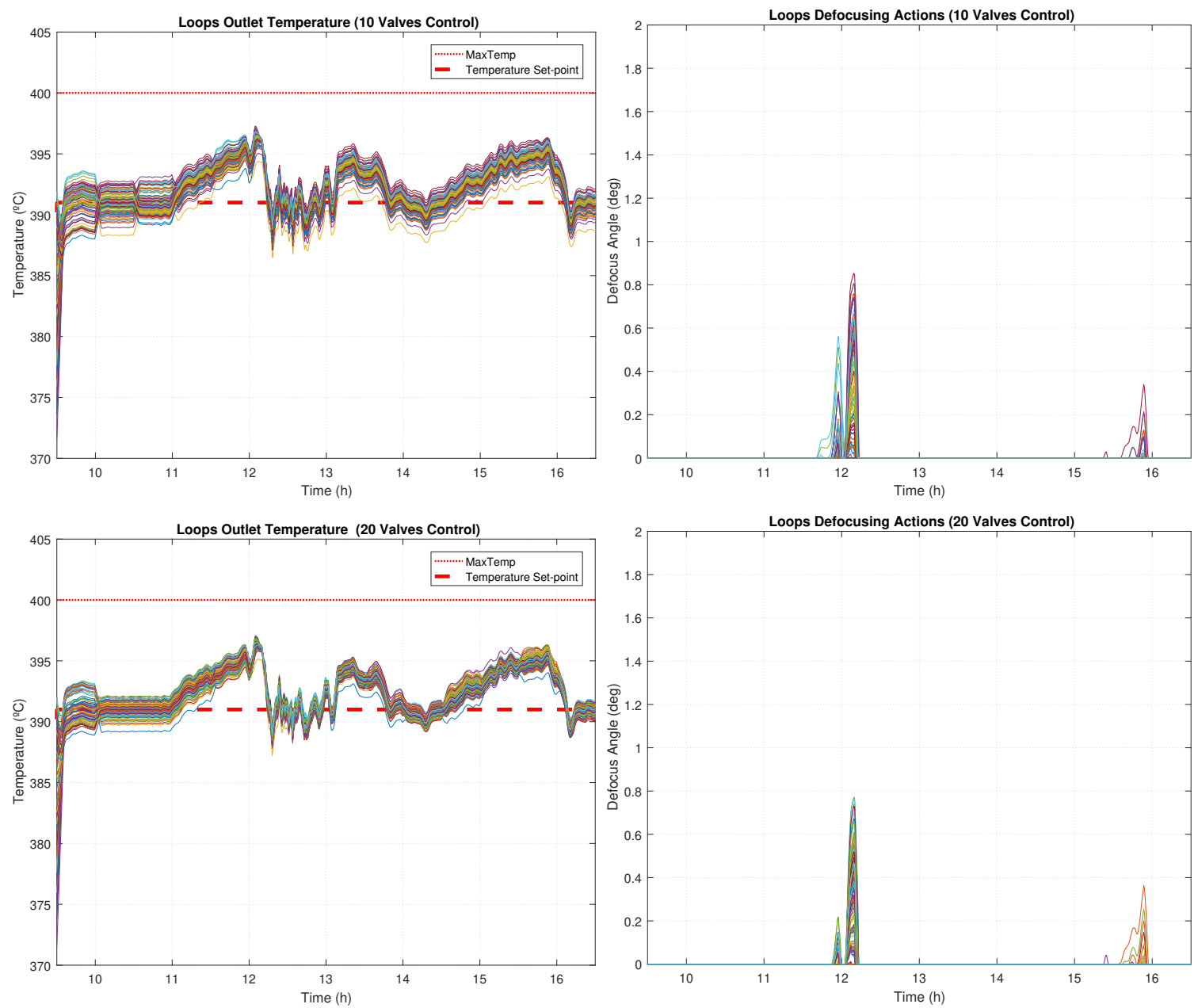

Figure 10 Loops temperatures (left) and defocus angles (right) results of the valve control strategy for thermal balance with 10 clusters (top) and 20 clusters (bottom) for a stable radiation.

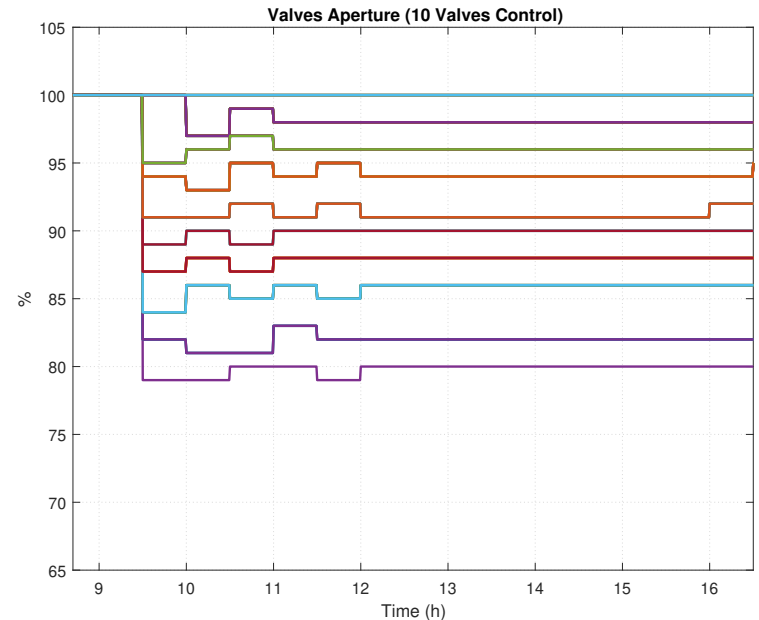

Figure 11 Valve control actions for the 10 clusters simulations with stable radiation.

A comparison of the total traveled defocus angles by each of the loops is shown in Fig. 13. As it can be seen, the defocus angles are now more distributed and the sum of all of them is smaller than when the field is not bal- anced. Table 4 shows the numerical results where it is finally checked that the number of actions and angles traveled with the thermal equilibrium has decreased considerably in the whole field.

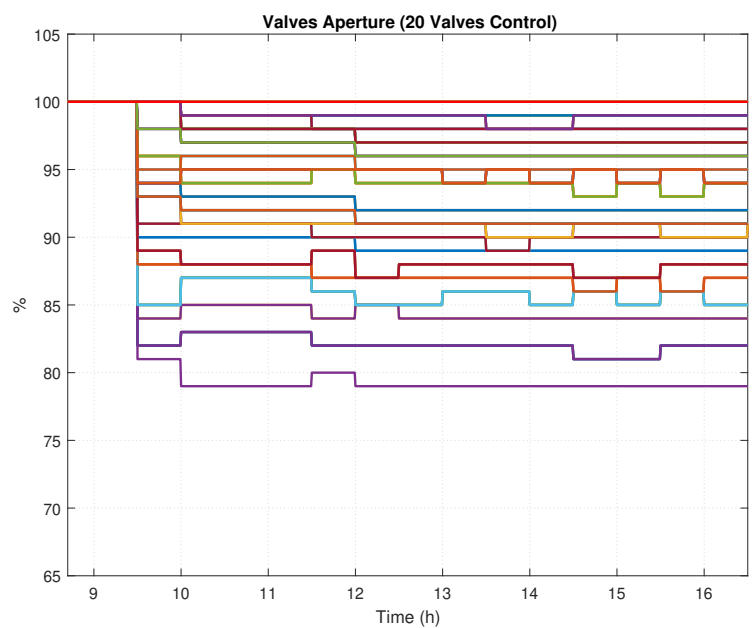

Figure 12 Valve control actions for the 20 clusters simulations with stable radiation. 


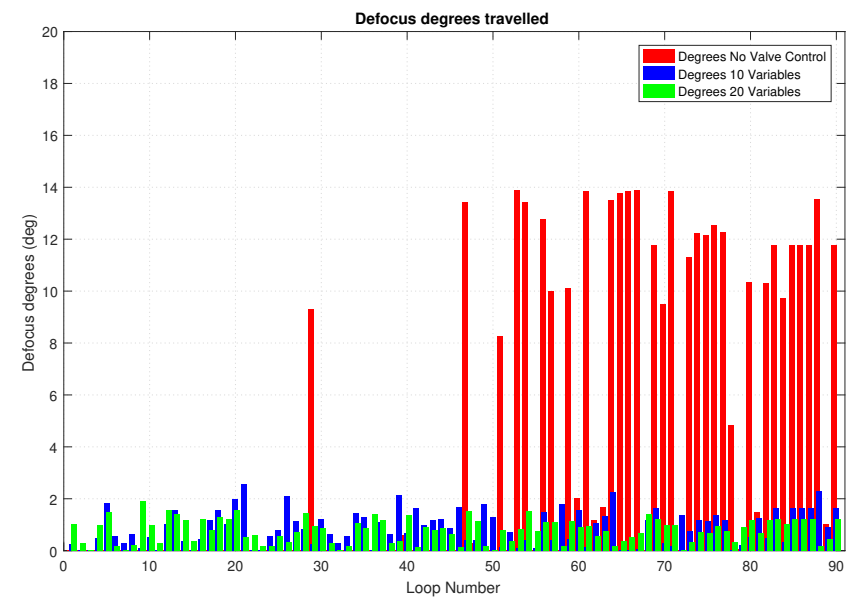

Figure 13 Loops traveled defocus angles comparison with stable radiation.

The case of medium but continuous transients is presented in Figs. 14, 15, 16, 17, 18 and 19.
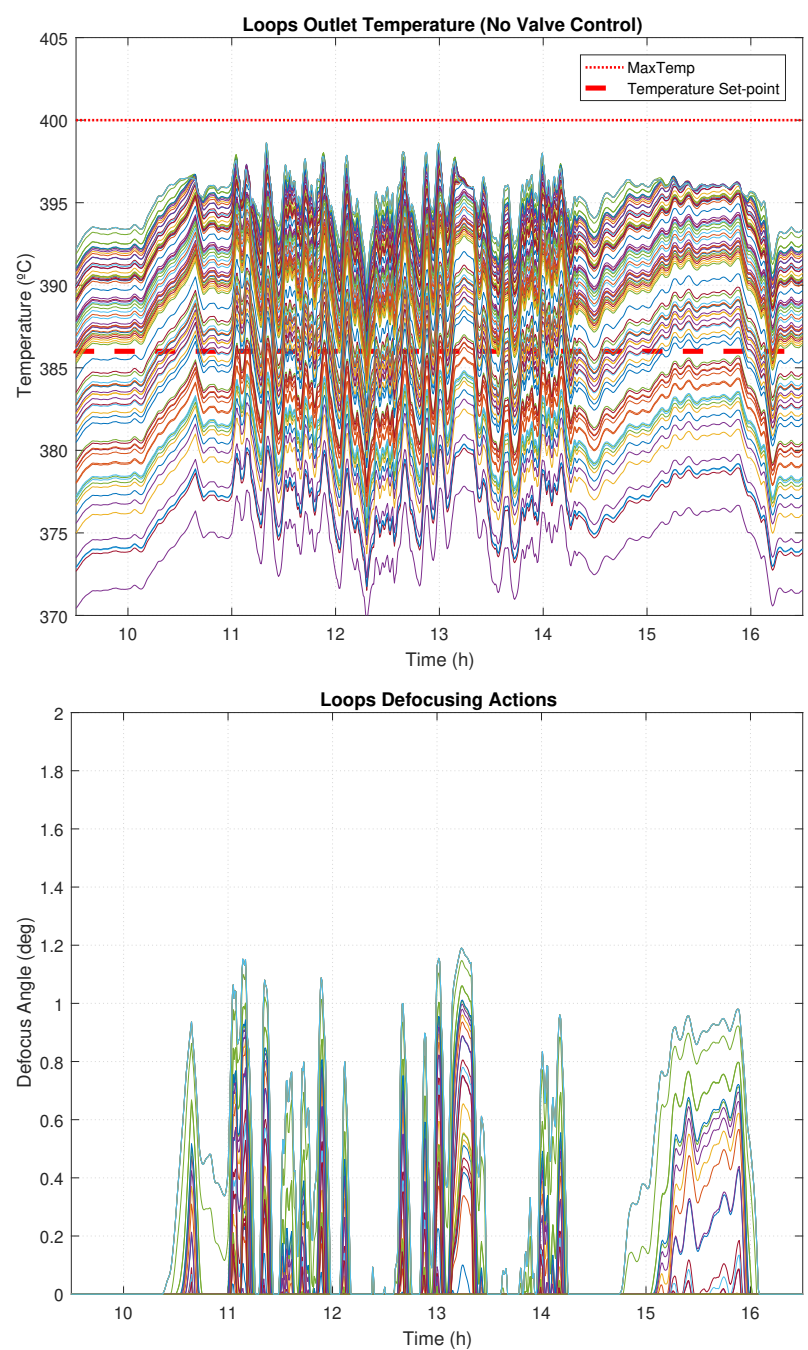

Figure 14 Loops temperatures (top) and defocus angles (bottom) when there is no valve control under transient radiation.

For this simulation, a clustering of 10 groups of loops has been applied. The case when no valve control is applied is presented in Fig. 14. It can be observed the disparity in the loops outlet temperatures and the defocusing control actions needed for the most efficient loops to avoid oil degradation. Once more, the results of the outlet temperatures of the case with valve control show a clear success in the thermal balance of the field, see Fig. 16.
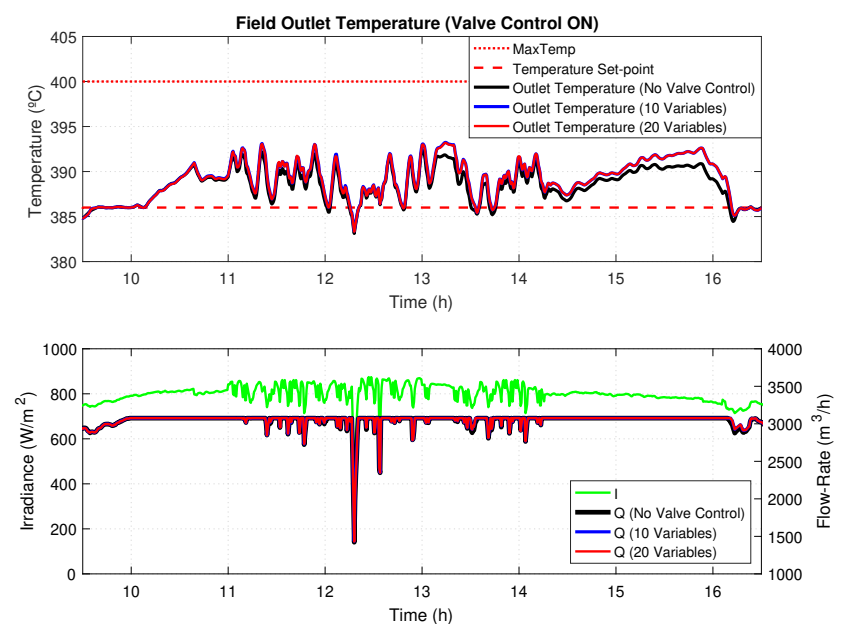

Figure 15 Field outlet temperature (top) and flow-rate (bottom) comparison with transient radiation.

Due to the irradiance transients, a lower temperature has been applied to ensure that the plant is in saturation and thus comply with the optimum operating temperature, $386{ }^{\circ} \mathrm{C}$. In fact, in Fig. 15 , where the comparison of the field outlet temperatures and flow-rates is shown, it is observed that said temperature is above the reference practically at all times, ensuring that the plant is in saturation.

When applying the proposed strategy it is possible to avoid $100 \%$ of the defocusing actions when there is no valve control. As in the previous case, the valve actions are shown in Figs. 17 and 18 is shown. The numerical results for this scenario are presented in table 5. The average difference in the outlet temperature of the loops is reduced from $20.5{ }^{\circ} \mathrm{C}$ to $4.3{ }^{\circ} \mathrm{C}$ approximately. Results show that a better homogenization can be achieved when a 20 valve control is applied. In this case, the average difference in the outlet temperature of the loops is reduced from 20.5 ${ }^{\circ} \mathrm{C}$ to $2.8{ }^{\circ} \mathrm{C}$ approximately.

The number of total control actions is lower than in the previous case. However, due to transients, defocus control actions when thermal balancing is not applied are much more aggressive, higher defocus angles and thus a higher number of traveled angle, something that will ultimately damage the actuators, structures and flexible hoses. 

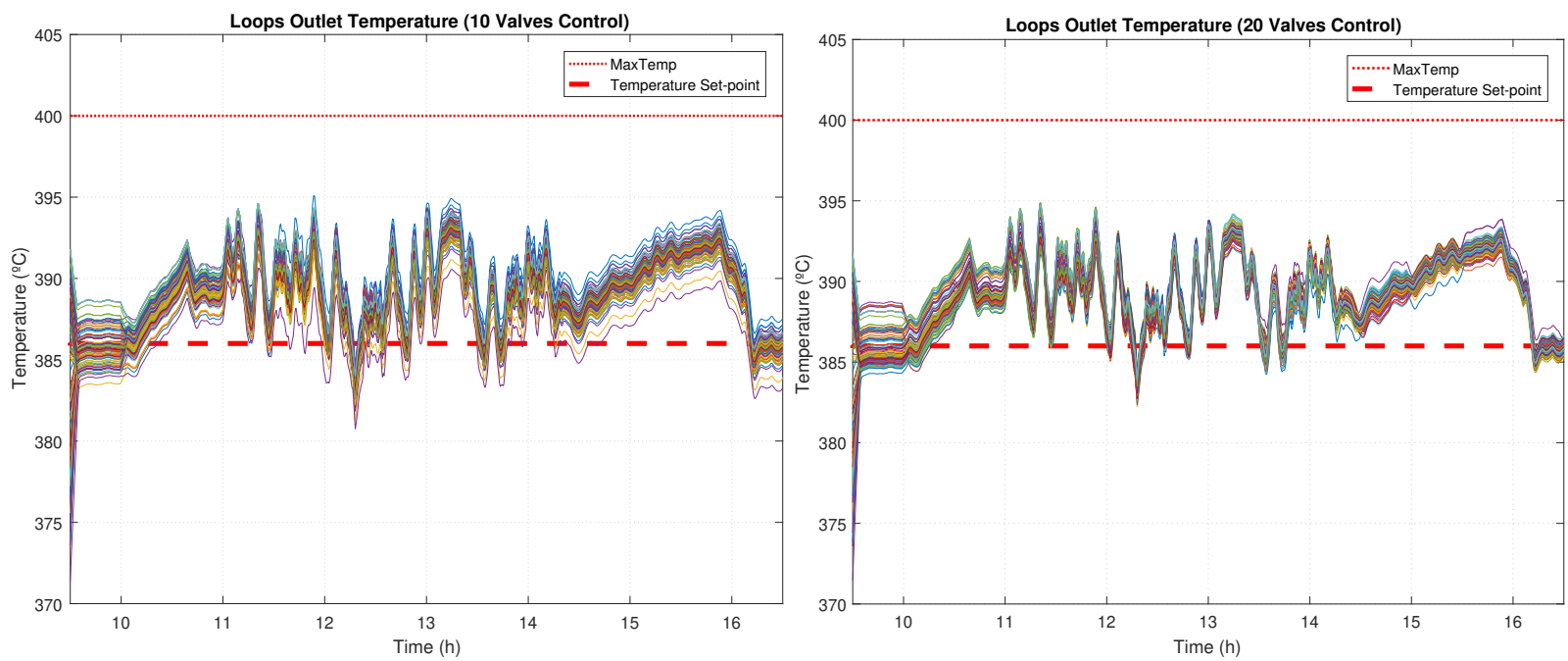

Figure 16 Loops temperatures for 10 variables (left) and 20 variables (right) results of the valve control strategy for thermal balance with transient radiation.

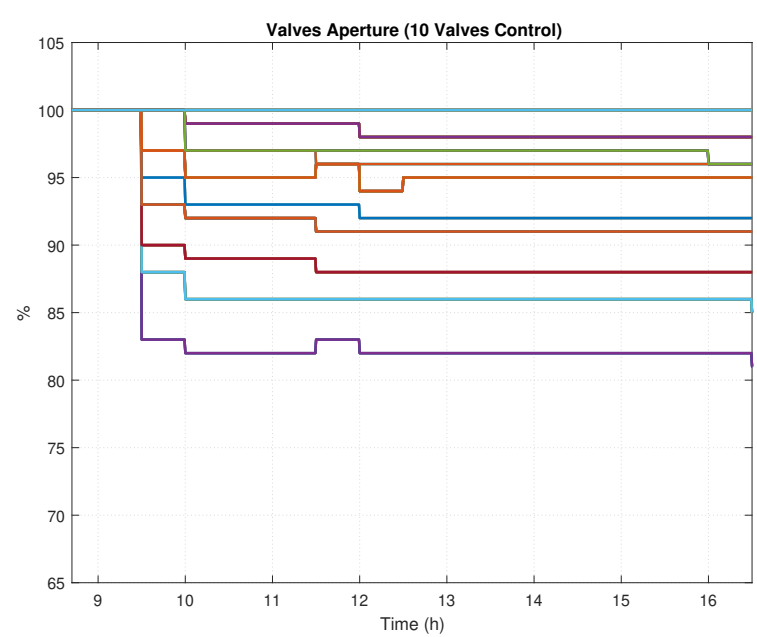

Figure 17 Valve control actions for 10 clusters simulations with transient radiation.

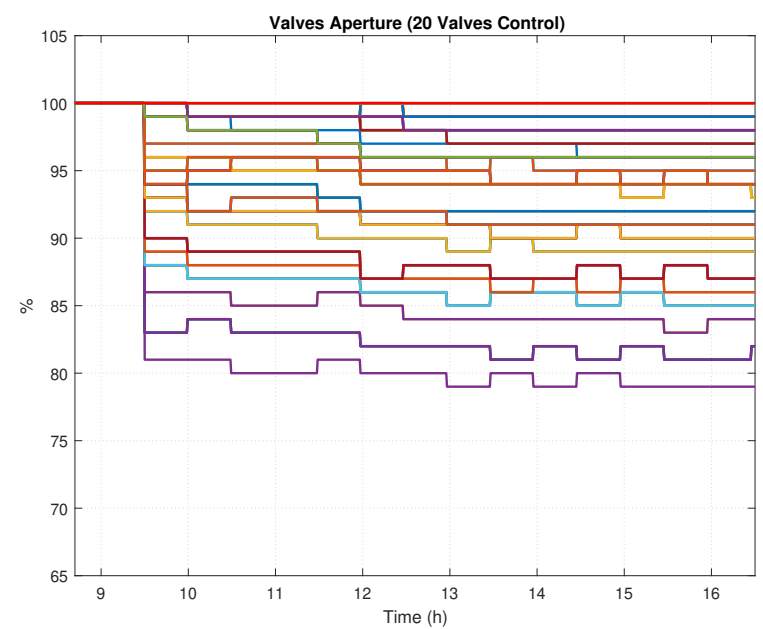

Figure 18 Valve control actions for 20 clusters simulations with transient radiation.

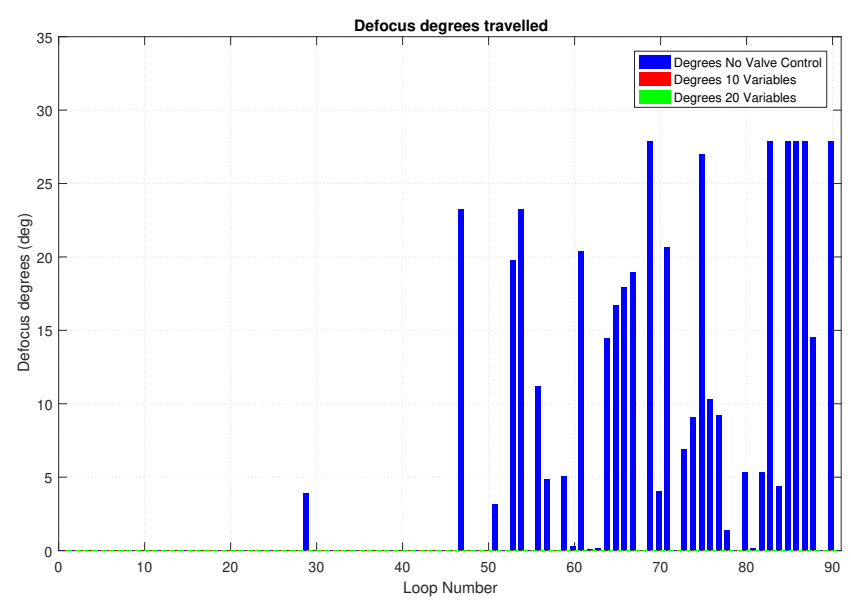

Figure 19 Loops traveled defocus angles comparison with transient radiation.

Table 4

Number of defocus and valve actions, case 1 (stable radiation).

\begin{tabular}{lccc}
\hline Control & Defocusing Actions & Valve Actions & Total Traveled Degrees \\
\hline No Valve Control & 18337 & 0 & 371.72 \\
\hline Valve Control 10 & 1964 & 350 & 79.87 \\
\hline Valve Control 20 & 1809 & 386 & 70.17 \\
\hline
\end{tabular}

Table 5

Number of defocus and valve actions, case 2 (transient radiation).

\begin{tabular}{lccc}
\hline Control & Defocusing Actions & Valve Actions & Total Traveled Degrees \\
\hline No Valve Control & 8021 & 0 & 469.52 \\
\hline Valve Control 10 & 0 & 223 & 0 \\
\hline Valve Control 20 & 0 & 444 & 0 \\
\hline
\end{tabular}

\section{Conclusion}

In this paper, within the framework of the OCONTSOLAR project, a case study regarding a nonlinear valve control model based strategy in a $50 \mathrm{MW}$ solar plant nonlinear 
simulation model has been presented. A simulation of the state of the field has been presented when the loops have different reflectivity values. Applying a single controller, based on global dynamics linear models, produces a thermal unbalance of the field that causes a great disparity in the outlet temperature of the loops. This causes that the most efficient loops have to be defocused more frequently to avoid HTF degradation temperature. An optimization has been presented to obtain a thermal balance of the field in which a loops clustering is used to reduce the computation time within the sampling time of the controller.

The results show that by applying a clustering of 10 and 20 groups of loops, the actions of the valves, calculated by the optimization process, considerably reduce the difference between the outlet temperature of loops. This results in a reduction of the defocus actions applied on the loops as well as possible energy losses. The reduction of the number of control signals to be applied will help to reduce the energy consumption required by these actuators as well as reduce the deterioration suffered by both the actuators and the structures of the loops and flexible hoses. In the first scenario, the control actions were reduced from 18337 defocus actions and 372 traveled degrees to 1809 and 1964 defocus actions and around 70 and 79 traveled degrees. In the second scenario, the defocus actions were completely eliminated, showing that it was not necessary to defocus the field, and that defocusing was due to thermal imbalance.

\section{Acknowledgments}

The authors would like to acknowledge the European Research Council for funding this work under Advanced Research Grant OCONTSOLAR (789051).

\section{References}

Alva, G., Liu, L., Huang, X., Fang, G., 2017. Thermal energy storage materials and systems for solar energy applications. Renewable and Sustainable Energy Reviews 68, 693 - 706 .

Andasol 1, Apr. 2019.

URL https://solarpaces.nrel.gov/andasol-1

Andrade, G., Pagano, D., Álvarez, J., Berenguel, M., 2013. A practical nmpc with robustness of stability applied to distributed solar power plants. Solar Energy 92, $106-122$.

Blanco, M. J., Santigosa, L. R., 2017. Advances in Concentrating Solar Thermal Research and Technology, 1st Edition. Woodhead Publishing.

Burkholder, F., Brandemuehl, M., Price, H., Netter, J., Kutscher, C., Wolfrum, E., 2007. Parabolic trough receiver thermal testing. In: Energy Sustainability, ASME 2007 Energy Sustainability Conference. pp. 961-970.

Camacho, E., Gallego, A., 2013. Optimal operation in solar trough plants: A case study. Solar Energy 95, $106-117$.

Camacho, E. F., Berenguel, M., Rubio, F. R., 1994. Application of a gain scheduling generalized predictive controller to a solar power plant. Control Engineering Practice 2 (2), 227-238.

Camacho, E. F., Berenguel, M., Rubio, F. R., 1997. Advanced Control of Solar Plants. Springer Science \& Business Media.

Camacho, E. F., Bordons, C., 2007. Model Predictive control, 2nd Edition. Springer-Verlag London.
Camacho, E. F., Rubio, F. R., Hughes, F. M., April 1992. Self-tuning control of a solar power plant with a distributed collector field. IEEE Control Systems 12 (2), 72-78.

Camacho, E. F., Soria, M. B., Rubio, F. R., Martínez, D., 2012. Control of Solar Energy Systems, 1st Edition. Springer-Verlag London.

Carmona, R., 1985. Analisis, modelado y control de un campo de colectores solares distribuidos con sistema de seguimiento en un eje. Ph.D. thesis. Universidad de Sevilla.

Cojocaru, E. G., Bravo, J. M., Vasallo, M. J., Santos, D. M., 2019. Optimal scheduling in concentrating solar power plants oriented to low generation cycling. Renewable Energy 135, $789-799$.

Extresol-1, Apr. 2019.

URL https://solarpaces.nrel.gov/extresol-1

Gallego, A., Camacho, E., 2012. Adaptative state-space model predictive control of a parabolic-trough field. Control Engineering Practice 20 (9), $904-911$.

Gallego, A. J., Yebra, L. J., Camacho, E. F., 2018. Gain scheduling model predictive control of the new tcp-100 parabolic trough field. IFAC-PapersOnLine 51 (2), 475 - 480, 9th Vienna International Conference on Mathematical Modelling.

Geyer, M., Lüpfert, E., Osuna, R., Esteban, A., Schiel, W., Schweitzer, A., Zarza, E., Nava, P., Langenkamp, J., Mandelberg, E., Sep. 2002. Eurotrough - parabolic trough collector developed for cost efficient solar power generation. In: 11th SolarPACES International Symposium on Concentrated Solar Power and Chemical Energy Technologies.

González-Roubaud, E., Pérez-Osorio, D., Prieto, C., 2017. Review of commercial thermal energy storage in concentrated solar power plants: Steam vs. molten salts. Renewable and Sustainable Energy Reviews 80, $133-148$.

Goswami, D., Kreith, F., Kreider, J., 2000. Principles of Solar Engineering., 2nd Edition. Taylor \& Francis.

Guzmán, Apr. 2019.

URL https://solarpaces.nrel.gov/guzman

Haykin, S., 2001. Kalman Filtering and Neural Networks. A WileyInterscience Publication.

He, G., Chen, Q., Kang, C., Xia, Q., Jul. 2016. Optimal offering strategy for concentrating solar power plants in joint energy, reserve and regulation markets. IEEE Transactions on Sustainable Energy 7 (3), 1245-1254.

Helioenergy II, Apr. 2019.

URL https://solarpaces.nrel.gov/helioenergy-2

Helios I, Apr. 2019. URL https://solarpaces.nrel.gov/helios-i

Ibersol Ciudad Real, Apr. 2019. URL ibersol-ciudad-real-puertollano

Kearney, D. W., 2007. Parabolic trough collector overview. Parabolic trough work-shop, NREL.

Lima, D. M., Normey-Rico, J. E., Santos, T. L. M., 2016. Temperature control in a solar collector field using filtered dynamic matrix control. ISA Transactions 62, $39-49$, sI: Control of Renewable Energy Systems.

Liu, M., Tay, N. S., Bell, S., Belusko, M., Jacob, R., Will, G., Saman, W., Bruno, F., 2016. Review on concentrating solar power plants and new developments in high temperature thermal energy storage technologies. Renewable and Sustainable Energy Reviews 53, 1411 -1432 .

Lloyd, S. P., 1982. Least squares quantization in pcm. IEEE Transactions on Information Theory 28 (2), 129-137.

Lüpfert, E., Riffelmann, K., Price, H., Burkholder, F., Moss, T., May 2008. Experimental analysis of overall thermal properties of parabolic trough receivers. Journal of Solar Energy Engineering $130(2)$.

Majadas I, Apr. 2019.

URL https://solarpaces.nrel.gov/majadas-i

Mojave Solar Project, Apr. 2019.

URL https://solarpaces.nrel.gov/mojave-solar-project

Peiró, G., Prieto, C., Gasia, J., Jové, A., Miró, L., Cabeza, L. F., 2018. Two-tank molten salts thermal energy storage system for solar power plants at pilot plant scale: Lessons learnt and rec- 
ommendations for its design, start-up and operation. Renewable Energy 121, $236-248$.

Pelay, U., Luo, L., Fan, Y., Stitou, D., Rood, M., 2017. Thermal energy storage systems for concentrated solar power plants. Renewable and Sustainable Energy Reviews 79, 82 - 100.

Pitz-Paal, R., 2018. Concept and status of concentrating solar power systems. EPJ Web Conf. 189, 00008.

Prieto, C., Rodríguez, A., Patiño, D., Cabeza, L. F., 2018. Thermal energy storage evaluation in direct steam generation solar plants. Solar Energy 159, 501 - 509 .

Risca, Apr. 2019.

URL https://solarpaces.nrel.gov/la-risca

Roca, L., Bonilla, J., Rodríguez-García, M. M., Palenzuela, P., de la Calle, A., Valenzuela, L., 2016. Control strategies in a thermal oil molten salt heat exchanger. AIP Conference Proceedings 1734 (1), 130017.

Romanenko, A., Castro, J. A., 2004. The unscented Kalman filter as an alternative to the EKF for nonlinear state estimation: a simulation case study. Computers and Chemical Engineering 28, 347-355.

Romero, M., González-Aguilar, J., 2014. Solar thermal csp technology. Wiley Interdisciplinary Reviews: Energy and Environment 3 (1), 42-59.

Sánchez, A. J., Gallego, A. J., Escaño, J. M., Camacho, E. F., Nov. 2018a. Event-based mpc for defocusing and power production of a parabolic trough plant under power limitation. Solar Energy 174, $570-581$.

Sánchez, A. J., Gallego, A. J., Escaño, J. M., Camacho, E. F., May 2018b. Temperature homogenization of a solar trough field for performance improvement. Solar Energy. 165C, 1-9.

Sánchez, A. J., Gallego, A. J., Escaño, J. M., Camacho, E. F., 2019. Adaptive incremental state space mpc for collector defocusing of a parabolic trough plant. Solar Energy 184, 105 - 114.

Sarbu, I., Sebarchievici, C., Jan. 2018. A comprehensive review of thermal energy storage. Sustainability 10 (1), 1-32.

SCHOTT Solar CSP GmbH, Apr. 2019. Schott ptr®70 receivers. URL https://www.us.schott.com/csp/english/ schott-solar-ptr-70-receivers.html

Simon, D., 2006. Optimal state estimation: Kalman, H infinity, and nonlinear approaches. John Wiley \& Sons, Inc, Hoboken, New Jersey.

Solaben 2, Apr. 2019.

URL https://solarpaces.nrel.gov/solaben-2

Solana Generating Station, Apr. 2019.

URL

https://solarpaces.nrel.gov/

solana-generating-station

Solnova 1, Apr. 2019.

URL https://solarpaces.nrel.gov/solnova-1

St-Pierre, M., Gringras, D., 2004. Comparison between the unscented kalman filter and the extended kalman filter for the position estimation module of an integrated navigation information system. IEEE Intelligent Vehicles Symposium 0-7803-8310-9/04, 831-835.

System Advisor Model (SAM). NREL, Sep. 2018.

URL https://sam.nrel.gov/

Therminol VP1 HTF, Apr. 2019.

URL https://www.therminol.com/products/Therminol-VP1

Wang, Y., Qiu, Z., Qu, X., 2017. An improved unscented kalman filter for discrete nonlinear systems with random parameters. Discrete Dynamics in Nature and Society, 1-10. 